\title{
Risk factors associated with prevalent and incident syphilis among an HIV-infected cohort in Northeast China
}

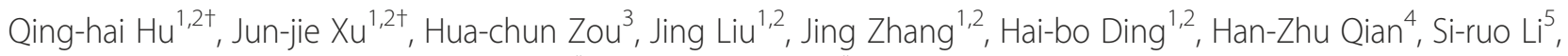
Yu Liu ${ }^{4}$, Yong-jun Jiang ${ }^{1,2}$, Hong Shang ${ }^{1,2^{*}}$ and Ning Wang ${ }^{1,6^{*}}$

\begin{abstract}
Background: Sexually transmitted infections (STIS) increase HIV infectivity through local inflammatory processes. Prevalent and incident STIs among people who live with HIV/AIDS (PLWHA) are indicators of high-risk sexual behaviors and imply potential spread of HIV. Little is known about the prevalence and incidence of concurrent syphilis and associated risk behaviors among PLWHA in China.

Methods: A retrospective cohort study was conducted among PLWHA who attended the outpatient clinic of a designated AIDS treatment hospital in Shenyang, China, between March 2009 and May 2013. Physical examinations and syphilis serology were conducted at each visit. A questionnaire on demographic characteristics was also collected.

Results: A total of 1010 PLWHA were enrolled, of whom 77.0\% were men who have sex with men (MSM). The baseline syphilis prevalence among PLWHA was 19.8\% (95\% confidence interval [CI]:17.3-22.3\%). During follow-up, 78.3\% retained in the cohort, and contributed a median follow-up of 9.4 months (interquartile range: 5.9-18.7 months). Syphilis incidence among PLWHA was 18.7 (95\% Cl: 15.5-21.8) per 100 person years. Mulitvariate logistic analysis showed that receiving antiretroviral therapy (ART) (adjusted OR [aOR] $=0.48$ ), older age ( $\geq 40$ years vs. $\leq 24$ years, aOR $=2.43$ ), being MSM $(\mathrm{aOR}=2.30)$ and having higher baseline HIV viral load (>100000 copies/mL vs. $\leq 100000$ copies $/ \mathrm{mL}, \mathrm{aOR}=1.56)$ were independent predictors for syphilis infection among PLWHA at enrollment ( $p<0.05$ for all). Mulivariate Cox regression found that receiving ART (adjusted hazard ratio $[\mathrm{aHR}]=1.81$ ), older age ( $\geq 40$ years vs. $\leq 24$ years, aHR: 5.17 ) and MSM status (aHR $=2.68)$ were independent risk factors for syphilis seroconversion (each $p<0.05)$.
\end{abstract}

Conclusions: Syphilis prevalence and incidence were high among PLWHA in Shenyang. A campaign focusing on detection and treatment of syphilis among PLWHA is urgently needed, especially one with a focus on MSM who are at a higher risk for syphilis.

Keywords: Retrospective cohort study, Syphilis, Prevalence, Incidence, Antiretroviral therapy (ART)

\section{Background}

China has witnessed a rapid increase of sexually transmitted infections (STIs), including syphilis and HIV in the past decade [1,2]. The national sentinel surveillance in 2009 showed that syphilis prevalence was $2.4 \%$ among female

\footnotetext{
*Correspondence: hongshang100@hotmail.com; wangnbj@163.com ${ }^{\dagger}$ Equal contributors

'Key Laboratory of AIDS Immunology of National Health and Family Planning Commission, Department of Laboratory Medicine, The First Affiliated Hospital, China Medical University, Shenyang 110001, P. R. China ${ }^{6}$ National Center for AIDS/STD Control and Prevention, Chinese Center for Disease Control and Prevention, Beijing, China

Full list of author information is available at the end of the article
}

sex workers (FSWs), 3.4\% among people who inject drugs (PWID), and 9.1\% among men who have sex with men (MSM) [1]. The population prevalence of syphilis in China was 32.0 per 100,000 people in 2011 [3] which was over 7 times as high as that in the US (4.5 per 100,000 people) [4] and the UK (5.6 per 100,000 people) [5]. In 2008, the prevalence of active syphilis among MSM was $12.2 \%$ in China, which was lower than that in Thailand (21.6\%) but higher than that in Indonesia (4.0\%) [6]. Sexual transmission had become the major route of HIV transmission in China in recent years [7]. Of 70,000 newly reported HIV/AIDS cases in the first nine months of 2013, heterosexual transmission 
accounted for $69.1 \%$ and MSM transmission accounted for $20.8 \%$ of all cases [8].

Globally the majority of HIV prevention programs usually focus on HIV negative individuals who are at high risk for HIV infection $[9,10]$. However, recently researchers realized that it may be more efficient to prevent HIV if we target people living with HIV/AIDS (PLWHA) ("positive prevention"), as they really serve as the sources of HIV transmission [11]. A meta-analysis showed that positive preventions were efficacious in reducing unprotected sex and acquisition of STIs [12]. The concept of Treatment as prevention strategy was raised and investigated quite intensively in recent years, and antiretroviral therapy (ART) can remarkably decrease the risk of transmitting HIV through reducing viral load (VL) among PLWHA [13,14]. HIV-1 RNA in seminal plasma may decline more slowly than that in blood and could be detected with undetectable HIV-1 RNA in blood plasma when PLWHA experience ART $[15,16]$, which points to the potential risk for HIV transmission via unprotected sexual behaviors. Moreover, ART may lead to complacent as people feel that they may live a long life with HIV and restore sexual desire as well as physical and immunological functions $[17,18]$. Because of sharing a common mode of sexual transmission, syphilis and HIV infection have significant epidemic synergistic. Syphilis incidence is considered an indicator of high-risk sexual behaviors $[19,20]$. Therefore, it is useful to understand the risk for HIV transmission among PLWHA by measuring their risk for syphilis transmission [21]. In addition, among individuals diagnosed with HIV who are not yet eligible for ART, treatment of co-infections including syphilis may offer an important alternative approach to reducing HIV VL and decreasing HIV transmission risk [22]. Little is known about the risk for syphilis transmission among PLWHA and its correlation with ART and sexual behaviors [23]. In this retrospective cohort study we aimed to evaluate both syphilis prevalence and incidence among PLWHA in Northeast China.

\section{Methods}

\section{Study population and participants enrollment}

This retrospective cohort study was conducted among HIV-infected patients in Shenyang City in Northeast China. HIV status was based on positive test results from two peripheral blood samples by HIV ELISA and confirmed by western blot (Gene labs Diag. Singapore). All HIV testing sites were certified by the National AIDS Reference Laboratory at China CDC. Participants were recruited from The First Affiliated Hospital of China Medical University (CMU), which was one of two designated hospitals providing free ART in Shenyang City. Since 2002, PLWHA in China with a $\mathrm{CD}_{4}^{+} \mathrm{T}$ cell counts of 200 cells $/ \mathrm{mm}^{3}$ or less, total lymphocyte counts of less than 1200 cells $/ \mathrm{mm}^{3}$, or WHO disease stage 3 or 4 have been eligible for free combination antiretroviral therapy. In 2008, the $\mathrm{CD}_{4}^{+} \mathrm{T}$ cell counts threshold for treatment was increased to 350 cells/ $\mathrm{mm}^{3}$ [24]. Between March 2009 and May 2013, patients who were scheduled for a regular visit at the HIV outpatient clinic in The First Affiliated Hospital of CMU were invited to participate in a baseline assessment. Eligible participants were those who: were 18 years or older and were able and willing to provide written informed consent. Baseline syphilis serological test was conducted to assess prevalent syphilis. Syphilis un-infected patients were followed up every 6 months to assess incident syphilis. During the follow-up, we calculated survival as time from baseline initiation to syphilis seroconversion or censoring. Patients were censored at dropout, loss to follow-up, or on May 31, 2013, whichever came first. Those who were diagnosed with syphilis infection were referred to the STI clinic in the same hospital for treatment. Figure 1 shows the study procedures.

Ethical approval was obtained from the institutional review board of The First Affiliated Hospital of CMU prior to the commencement of the study.

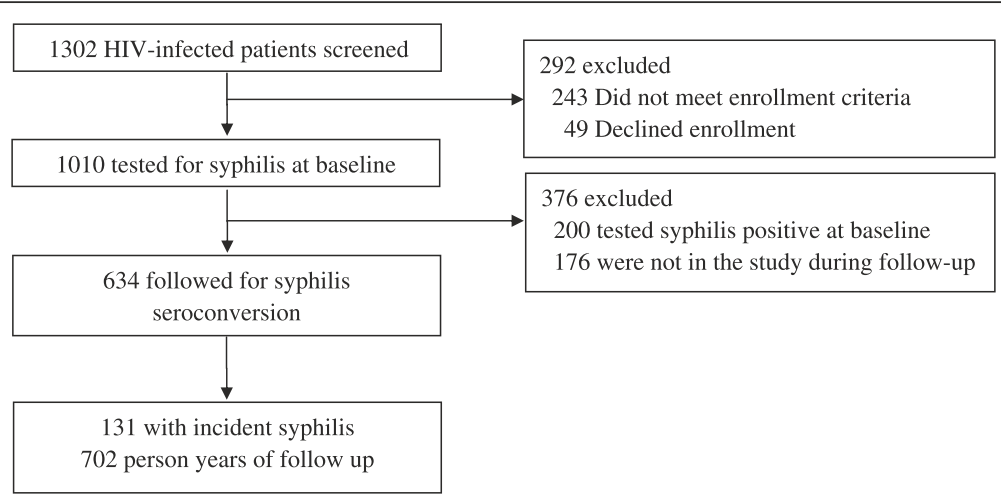

Figure 1 Procedure of enrollment and follow-up. A total of 1302 participants were invited, 243 did not meet enrollment criteria, 49 declined enrollment. A total of 1010 participants were included at baseline. Of the 810 participants who were syphilis seronegative at baseline, 634 completed at least one follow-up visit. 
Table 1 Characteristics of PLWHA with prevalent and incident syphilis in Shenyang

\begin{tabular}{|c|c|c|c|c|c|c|c|}
\hline \multirow[t]{2}{*}{ Characteristic } & \multicolumn{3}{|c|}{ Syphilis infection at baseline } & \multicolumn{4}{|c|}{ Syphilis seroconversion during follow-up } \\
\hline & $\begin{array}{l}\text { No. of } \\
\text { participants }\end{array}$ & $\begin{array}{l}\text { Seropositive } \\
\text { cases }\end{array}$ & $\begin{array}{l}\text { Prevalence } \\
(\%)\end{array}$ & $\begin{array}{l}\text { No. of } \\
\text { participants }\end{array}$ & $\begin{array}{l}\text { Person-years } \\
\text { (PY) }\end{array}$ & $\begin{array}{l}\text { Incident } \\
\text { cases }\end{array}$ & $\begin{array}{l}\text { Incidence } \\
\text { (per } 100 \mathrm{PY} \text { ) }\end{array}$ \\
\hline Overall & 1010 & 200 & 19.8 & 634 & 702.3 & 131 & 18.7 \\
\hline \multicolumn{8}{|l|}{ Gender } \\
\hline Female & 68 & 4 & 5.9 & 51 & 40.6 & 3 & 7.4 \\
\hline Male & 942 & 196 & 20.8 & 583 & 661.8 & 128 & 19.3 \\
\hline \multicolumn{8}{|l|}{ Age (year) } \\
\hline Median(IQR) & $35(27-46)$ & & & $35(27-46)$ & & & \\
\hline$\leq 24$ & 142 & 22 & 15.5 & 92 & 124.8 & 8 & 6.4 \\
\hline 25-39 & 461 & 77 & 16.7 & 299 & 353.7 & 43 & 12.2 \\
\hline$\geq 40$ & 407 & 101 & 24.8 & 243 & 223.9 & 80 & 35.7 \\
\hline \multicolumn{8}{|l|}{ Ethnicity } \\
\hline Han & 883 & 182 & 20.6 & 552 & 607.0 & 115 & 19.0 \\
\hline Other ethnicities & 127 & 18 & 14.2 & 82 & 95.3 & 16 & 16.8 \\
\hline \multicolumn{8}{|l|}{ Marital status } \\
\hline Single & 522 & 102 & 19.5 & 317 & 376.0 & 54 & 14.4 \\
\hline Married & 330 & 62 & 18.8 & 213 & 219.3 & 44 & 20.1 \\
\hline Divorced & 158 & 36 & 22.8 & 104 & 107.1 & 33 & 30.8 \\
\hline \multicolumn{8}{|l|}{ Occupation } \\
\hline Employed & 645 & 129 & 20.0 & 415 & 461.3 & 90 & 19.5 \\
\hline Unemployed & 198 & 36 & 18.2 & 123 & 120.0 & 24 & 20.0 \\
\hline Retired & 76 & 22 & 29.0 & 43 & 46.5 & 14 & 30.1 \\
\hline Student & 91 & 13 & 14.3 & 53 & 74.7 & 3 & 4.0 \\
\hline \multicolumn{8}{|l|}{ Education } \\
\hline Less than high school & 351 & 77 & 21.9 & 209 & 225.4 & 46 & 20.4 \\
\hline High school or more & 659 & 123 & 18.7 & 425 & 476.9 & 85 & 17.8 \\
\hline \multicolumn{8}{|l|}{ Shenyang resident } \\
\hline Yes & 885 & 181 & 20.5 & 560 & 601.4 & 115 & 19.1 \\
\hline No & 125 & 19 & 15.2 & 74 & 100.9 & 16 & 15.9 \\
\hline \multicolumn{8}{|l|}{ HIV transmission route } \\
\hline Heterosexual & 146 & 16 & 11.0 & 103 & 88.2 & 15 & 17.0 \\
\hline MSM & 778 & 171 & 22.0 & 478 & 570.0 & 111 & 19.5 \\
\hline $\begin{array}{l}\text { Others (injection drug use, } \\
\text { blood, unknown) }\end{array}$ & 86 & 13 & 15.1 & 53 & 44.2 & 5 & 11.3 \\
\hline \multicolumn{8}{|l|}{ HIV diagnosis venue } \\
\hline $\mathrm{VCT}$ & 277 & 54 & 19.5 & 182 & 244.9 & 41 & 16.7 \\
\hline Hospital & 366 & 87 & 23.8 & 242 & 281.3 & 59 & 21.0 \\
\hline $\begin{array}{l}\text { Others (blood donation, } \\
\text { physical exam, etc.) }\end{array}$ & 57 & 6 & 10.5 & 48 & 70.0 & 5 & 7.2 \\
\hline Unknown & 310 & 53 & 17.1 & 162 & 106.2 & 26 & 24.5 \\
\hline \multicolumn{8}{|l|}{ ART at baseline } \\
\hline No & 687 & 159 & 23.1 & 385 & 501.0 & 68 & 13.6 \\
\hline Yes & 323 & 41 & 12.7 & 249 & 201.3 & 63 & 31.3 \\
\hline
\end{tabular}


Table 1 Characteristics of PLWHA with prevalent and incident syphilis in Shenyang (Continued)

\begin{tabular}{|c|c|c|c|c|c|c|c|}
\hline \multicolumn{8}{|c|}{ Time since HIV diagnosis (year) } \\
\hline$\leq 2$ & 730 & 156 & 21.4 & 439 & 514.1 & 79 & 15.4 \\
\hline$>2$ & 280 & 44 & 15.7 & 195 & 188.2 & 52 & 27.6 \\
\hline \multicolumn{8}{|c|}{ Baseline $\mathrm{CD}_{4}^{+} \mathrm{T}$ cell counts(counts $/ \mathrm{mm}^{3}$ ) } \\
\hline$\geq 500$ & 152 & 28 & 18.4 & 95 & 126.3 & 20 & 21.1 \\
\hline $350-499$ & 255 & 40 & 15.7 & 173 & 194.1 & 41 & 23.7 \\
\hline $200-349$ & 331 & 62 & 18.7 & 214 & 226.7 & 36 & 16.8 \\
\hline$<200$ & 246 & 65 & 26.4 & 142 & 137.7 & 30 & 21.1 \\
\hline Unknown & 26 & 5 & 19.2 & 10 & 17.5 & 4 & 40.0 \\
\hline \multicolumn{8}{|c|}{ Baseline VL (copies/mL) } \\
\hline$\leq 100,000$ & 599 & 118 & 19.7 & 378 & 455.6 & 77 & 16.9 \\
\hline$>100,000$ & 148 & 46 & 31.1 & 72 & 85.5 & 13 & 15.2 \\
\hline Unknown & 263 & 36 & 13.7 & 184 & 161.2 & 41 & 25.4 \\
\hline
\end{tabular}

IQR: interquartile range; VCT: voluntary counseling and testing; ART: antiretroviral therapy; VL: viral load; PY: person year.

\section{Data collection}

At baseline, patients were asked to self-complete an anonymous questionnaire on demographic characteristics, HIV history including date and venues of HIV diagnosis, transmission route, and ART experience. HIV VL and $\mathrm{CD}_{4}^{+} \mathrm{T}$ cell counts were also tested as part of regular care. The blood specimens collected at baseline and 6-monthly follow-up visits were also tested for syphilis infection. After explanation of study, informed consent was obtained from all participants.

\section{Laboratory testing}

Syphilis screening serological test was performed using rapid plasma reagin (RPR; Shanghai Kehua Bio-engineering Co., Ltd, China). Positive RPR results were confirmed using Treponema Pallidum particle assay (Serodia TPPA; Fujirebio, Tokyo, Japan). Subjects who were plasma positive for both TPPA and RPR were considered as current infection. RPR negative participants at baseline who turned to be positive for both TPPA and RPR at follow-up visits were defined as syphilis seroconversion event. In addition, TPPA negative participants at baseline who turned to be TPPA positive were eligible for syphilis seroconversion during the follow-up period. $\mathrm{CD}_{4}^{+} \mathrm{T}$ cell counts were determined by flow cytometry (BD Bioscience San Diego, CA, USA). Plasma HIV-1 RNA copy was measured by a commercial HIV RNA quantitative detection assay, COBAS AmpliPrep/COBAS TaqMan HIV-1 Test (Roche, Germany), with a detection limit of 40 copies $/ \mathrm{mL}$ in plasma. All tests were performed according to the manufacturers' instructions.

\section{Data analysis}

Demographic and HIV history variables were compared between participants with prevalent syphilis at baseline and those without; and between those who seroconverted during follow-up and those who did not. We analyzed covariates including sex, age ( $\leq 24,25-39$, and $\geq 40$ years), ethnicity, marital status, occupation, education, HIV transmission route (heterosexual, MSM and others), HIV diagnosis venues (voluntary counseling and testing [VCT], hospital, others and unknown), baseline $\mathrm{CD}_{4}^{+} \mathrm{T}$ cell counts $\left(<200,200-349,350-499\right.$, and $\geq 500$ counts $\left./ \mathrm{mm}^{3}\right)$, baseline VL $(\leq 100000$ and $>100000$ copies/mL). Logistic regression was performed to assess factors associated with prevalent syphilis infection at baseline. Cox proportional hazard regression was used to determine the adjusted hazard ratio (aHR) for factors associated with incident syphilis infection. Syphilis seroconversion was estimated to occur at the midpoint of the interval between the last negative test and the subsequent follow-up positive test. Syphilis incidence rate and its 95\% confidence interval (CI) were calculated assuming Poisson distribution. Variables with $P<0.20$ in univariate analysis were included in the multivariate logistic or Cox regression models. Only variables with $P<0.05$ were kept in the final multivariate models. Double data entries were performed using EpiData software (The Epi Data Association Odense, Denmark, version 3.02). Data were analyzed using SAS 9.1 (SAS Institute Inc., Cary, NC).

\section{Results}

Demographic characteristics of study participants

As shown in Figure 1, a total of 1302 PLWHA who were registered at the HIV clinic were invited to participate in the study, 243 did not meet enrollment criteria, 49 declined enrollment. Therefore a total of 1010 participants were included in the estimation of HIV prevalence at baseline. Of the 810 participants who were syphilis seronegative at baseline, $78.3 \%(634 / 810)$ completed at least one follow-up visit and contributed a median follow-up of 9.4 months (interquartile range [IQR]: 5.9-18.7 months). 
Table 2 Factors associated with syphilis infection at baseline among PLWHA in Shenyang

\section{Factor}

Gender

Female

Male

Age(year)

$$
\begin{aligned}
& \leq 24 \text { years } \\
& 25-39 \text { years } \\
& \geq 40 \text { years }
\end{aligned}
$$

Ethnicity

$$
\text { Other ethnicities }
$$

\section{Marital status}

$$
\begin{gathered}
\text { Single } \\
\text { Married } \\
\text { Divorced } \\
\text { Occupation } \\
\text { Employed } \\
\text { Unemployed } \\
\text { Retired } \\
\text { Student }
\end{gathered}
$$

\section{Occupation}

\section{Education}

Less than high school

High school or more

\section{Shenyang resident}

Yes

No

HIV transmission route

Heterosexual

MSM

Others (injection drug use, blood, unknown)

\section{HIV Diagnosis venue}

VCT

Hospital

Others (blood donation,

physical exam, etc.)

Unknown

\section{ART at baseline}

$$
\text { No }
$$

Yes

Time since HIV diagnosis (year)

$\leq 2$

$>2$

\section{OR $(95 \% \mathrm{Cl})$}

1.00

$4.20(1.51-11.69)$

1.00

$1.09(0.65-1.83)$

0.734

0.023

$1.80(1.08-2.99)$

1.00

$0.64(0.38-1.08)$

0.091

1.00

$0.95(0.67-1.35)$

0.786

$1.22(0.79-1.87)$

1.00

$0.89(0.59-1.34) \quad 0.573$

$1.63(0.96-2.77) \quad 0.072$

$0.67(0.36-1.24)$

0.199

1.00

$0.82(0.59-1.12)$

0.214

1.00

$0.70(0.42-1.17)$

1.00

$2.29(1.33-3.95)$

0.003

$2.30(1.30-4.08)$

0.004

$1.45(0.66-3.18)$

0.357

$1.33(0.59-2.97)$

0.488

1.00

$1.29(0.88-1.89)$

0.195

$1.42(0.94-2.13)$

0.095

$0.49(0.20-1.19)$

0.115

$0.63(0.25-1.56)$

0.314

$0.85(0.56-1.30)$

0.453

$0.75(0.49-1.17)$

0.208

1.00

$0.48(0.33-0.70)$

$<0.001$

$0.48(0.31-0.73)$
0.395

0.001
1.00

$0.69(0.48-0.99)$ 
Table 2 Factors associated with syphilis infection at baseline among PLWHA in Shenyang (Continued)

\begin{tabular}{|c|c|c|c|c|}
\hline \multicolumn{5}{|c|}{ Baseline $\mathrm{CD}_{4}^{+} \mathrm{T}$ counts(counts $/ \mathrm{mm}^{3}$ ) } \\
\hline$\geq 500$ & 1.00 & & & \\
\hline $350-499$ & $0.82(0.48-1.40)$ & 0.475 & & \\
\hline $200-349$ & $1.02(0.62-1.67)$ & 0.935 & & \\
\hline$<200$ & $1.59(0.97-2.62)$ & 0.068 & & \\
\hline Unknown & $1.05(0.37-3.04)$ & 0.922 & & \\
\hline \multicolumn{5}{|c|}{ Baseline VL(copies/mL) } \\
\hline$\leq 100000$ & 1.00 & & & \\
\hline$>100000$ & $1.84(1.23-2.75)$ & 0.003 & $1.56(1.02-2.40)$ & 0.040 \\
\hline Unknown & $0.65(0.43-0.97)$ & 0.035 & $0.82(0.54-1.26)$ & 0.361 \\
\hline
\end{tabular}

VCT: voluntary counseling and testing; ART: antiretroviral therapy; VL: viral load.

Table 1 shows the demographic characteristics and HIV history stratified by syphilis serostatus at baseline and syphilis seroconversion during follow-up. At baseline, the median age was 35 years (IQR: 27-46); $87.4 \%$ were ethnic Han; $93.3 \%$ were male; $87.6 \%$ were Shenyang residents, $34.8 \%$ had an education of high school or higher; $51.7 \%$ were single, $32.7 \%$ were currently married and $15.6 \%$ were divorced; 77.0\% self-reported as being MSM.

Just over a quarter (27.4\%) of participants had been diagnosed with HIV at VCT venues, $36.2 \%$ in hospitals, and the rest through other ways such as HIV/AIDS research projects. Nearly one third (32.0\%) had prior ART. At baseline $15.1 \%, 25.3 \%, 32.8 \%$ and $24.4 \%$ had a $\mathrm{CD}_{4}^{+} \mathrm{T}$ cell counts of $\geq 500,350-499,200-349$ and $<200$ cells $/ \mathrm{mm}^{3}$, respectively. $\mathrm{CD}_{4}^{+} \mathrm{T}$ cells were not detected in $2.6 \%$ of participants. At baseline $59.3 \%$ and $14.7 \%$ had a $\mathrm{VL}$ of $\leq 100,000$ and $>100,000$ copies/mL, respectively. VL was not detected in $26.0 \%$ of participants.

Factors associated with seropositivity of syphilis at baseline The baseline seroprevalence of syphilis was 19.8\% (95\% CI: 17.3-22.3\%). Table 2 illustrates the factors associated with baseline syphilis infection. In the final multivariate logistic regression model, ART experience was negatively associated with syphilis infection (adjusted OR $[\mathrm{aOR}]=0.48,95 \%$ CI: $0.31-0.73)$, but older age ( $\geq 40$ years vs. $\leq 24$ years) $(\mathrm{aOR}=2.43,95 \% \mathrm{CI}: 1.42-4.15)$, being $\mathrm{MSM}(\mathrm{aOR}=$ 2.30, 95\% CI: 1.30-4.08), and having higher baseline VL $(>100,000$ copies/mL vs. $\leq 100000$ copies $/ \mathrm{mL})(\mathrm{aOR}=1.56$, 95\% CI: 1.02-2.40) were independently associated with a higher risk of syphilis infection (each $\mathrm{p}<0.05$ ).

Factors associated with seroconversion of syphilis during follow-up

Of the 634 eligible participants for syphilis incidence estimation, 131 (20.7\%) seroconverted during followup. The incidence rate was 18.7 (95\% CI: 15.5-21.8) per 100 person years (PY). Table 3 shows factors associated with syphilis seroconversion. ART experience (adjusted hazard ratio $[\mathrm{aHR}]=1.81,95 \% \mathrm{CI}: 1.25-2.62$ ), older age ( $\geq 40$ years vs. $\leq 24$ years) $(\mathrm{aHR}=5.17,95 \% \mathrm{CI}: 2.47-$ 10.84), and being MSM (aHR: 2.68, 95\% CI: 1.53-4.69) were independently associated with syphilis seroconversion (each $\mathrm{p}<0.05)$.

\section{Discussion}

STIs pose considerable health threats to PLWHA. In this study, we report on the first evaluation of both syphilis prevalence and incidence among an HIV-infected cohort in northeast China. The prevalence among PLWHA in Shenyang (19.8\%) is much higher than that among PLWHA in Taiwan (5.7\%) [25], Guangzhou (10.5\%) [26] and Liuzhou City (11.4\%) [27] in China. It is also higher than the average syphilis prevalence among PLWHA from a Meta analysis (9.5\%) [28]. Syphilis incidence among Shenyang PLWHA (18.7/100 PY) is significantly higher than that in Seoul, South Korea (4.57/100 PY) [29], and higher than the syphilis incidence among Sichuan PWID (4.71/100 PY) [30] and Xichang FSWs (6.23/100 PY) [31].

Syphilis can generate genital ulcers and increase the likelihood of HIV virus shedding. Additionally syphilis co-infection among PLWHA can increase the concentration of HIV RNA in blood plasma and decrease the number of $\mathrm{CD}_{4}^{+} \mathrm{T}$ cell counts [22], and may increase the risk for HIV transmission [32]. It's highly likely that high prevalent and incident syphilis may contribute to the spread of HIV which is a new threat to HIV prevention. Our findings provide important information to the development of syphilis screening and treatment program for PLWHA across China. Syphilis is a marker of unsafe sexual practices [20,21], and therefore the high syphilis prevalence and incidence indicated that PLWHA who had already known self HIV positive status may still engage in unprotected sex. Behavioral intervention can reduce HIV transmission risk among HIV positive MSM [33]. Efficient education programs including safer sexual behavioral interventions are urgently needed to reduce risk for STIs transmission among PLWHA in China. 
Table 3 Factors associated with syphilis seroconversion among PLWHA in Shenyang

\section{Factor}

Gender

Female

Male

Age (year)

$$
\begin{aligned}
& \leq 24 \text { years } \\
& 25-39 \text { years } \\
& \geq 40 \text { years }
\end{aligned}
$$

Ethnicity

$$
\text { Other ethnicities }
$$

\section{Marital status}

$$
\text { Single }
$$

Married

Divorced

\section{Occupation}

Employed

Unemployed

Retired

Student

\section{Education}

Less than high school

High school or more

\section{Shenyang resident}

Yes

No

\section{HIV transmission route}

Heterosexual

MSM

Others (injection drug use blood, unknown)

\section{HIV Diagnosis venue}

VCT

Hospital

Others (blood donation,

physical exam, etc.)

Unknown

\section{ART at baseline}

$$
\text { No }
$$

Yes

Time since HIV diagnosis (year)

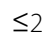

$>2$

\section{$\leq 2$}

\section{HR $(95 \% \mathrm{Cl})$}

1.00

$3.39(1.08-10.65)$

1.00

$1.79(0.84-3.81)$

$4.85(2.34-10.05)$

1.00

$0.91(0.54-1.53)$

0.713

1.00

$1.31(0.88-1.95)$

$2.00(1.29-3.08)$

1.00

$0.98(0.62-1.54)$

0.924

$1.58(0.90-2.77)$

0.112

$0.23(0.07-0.72)$

0.012

1.00

$0.89(0.62-1.27)$

0.503

$0.89(0.53-1.51)$

0.676

1.00

$1.45(0.84-2.49)$

$0.68(0.25-1.87)$

1.00

$2.82(1.13-7.03)$

0.026

$2.34(0.92-5.91)$

$3.05(1.17-7.98)$

1.00

$1.81(1.27-2.57)$

1.00

$1.57(1.10-2.23)$

.002

0.073

0.023

0.001

0.012
Adjusted HR $(95 \% \mathrm{Cl})$

P-value

037

$<0.001$

$1.86(0.87-3.98)$

0.108

$5.17(2.47-10.84)$

$<0.001$
$2.08(0.83-5.22)$

0.120

$1.92(0.76-4.87)$

0.171

$2.55(0.97-6.74)$

0.058

$1.81(1.25-2.62)$

0.002

$1.57(1.10-2.23)$ 
Table 3 Factors associated with syphilis seroconversion among PLWHA in Shenyang (Continued)

\begin{tabular}{lll}
\hline Baseline $\mathbf{C D}_{\mathbf{4}}^{+} \mathbf{T}$ cell counts $\left(\right.$ counts $\left./ \mathbf{m m}^{\mathbf{3}}\right)$ & \\
$\geq 500$ & 1.00 & \\
$350-499$ & $1.26(0.74-2.16)$ & 0.392 \\
$200-349$ & $0.92(0.53-1.59)$ & 0.764 \\
$<200$ & $1.26(0.71-2.22)$ & 0.428 \\
Unknown & $1.83(0.62-5.36)$ & 0.272 \\
Baseline VL(copies/mL) & & \\
$\leq 100000$ & 1.00 & 0.920 \\
$>100000$ & $0.97(0.54-1.75)$ & 0.207 \\
Unknown & $1.28(0.87-1.87)$ & \\
\hline
\end{tabular}

VCT: voluntary counseling and testing; ART: antiretroviral therapy; VL: viral load.

Conflicting results are provided by studies analyzing the association between ART experience and STIs transmission [34-36]. Our data show that the syphilis seropositive rate among ART patients was significantly lower than that among treatment naïve patients. The possible reasons for this may include: unrecovered immune status, degenerative sexual desires and lower frequency of unprotected sexual behaviors. Our study further shows that PLWHA who took ART had significantly increased syphilis incidence. This is consistent with the findings by Stolte, et al. in Amsterdam [34], but inconsistent with that by Huang, et al. in Taiwan [37]. Though ART correlate with substantially lowered HIV RNA levels and decreased HIV infectiveness among PLWHA [13,14], apart from beneficial clinical effects, treatment advances may have unintended effects on sexual behavior. Some evidence suggests that since ART became available, the prevalence of unprotected sex $[34,38]$ have increased. Sexually transmitted co-infections increase HIV infectiveness through local inflammatory processes and offset the ART treatment effect as being HIV secondary prevention. These findings suggest that, with the expansion of ART in China, health education, behavioral interventions and STIs monitoring should be strengthened among ART patients.

MSM (vs. heterosexual), current use of ART at baseline, and older age ( $\geq 40$ vs. $\leq 24$ years) were independently correlated with baseline syphilis infection. MSM status is also a risk factor for incident syphilis infection, which is consistent with the literature [36,39]. In China MSM accounted for $0.3 \%$ of the total reported HIV/AIDS cases in 2006. This figure rapidly increased to $13.0 \%$ in 2011 [7]. A large number of MSM engage in unprotected sexual behaviors and multiple sexual partnership [40,41] which place them at risk for both HIV and syphilis infections. Our findings suggest that HIV-infected MSM should be given priority to receive syphilis screening and treatment in Shenyang city.

This study found that the participants aged 40 or older had a significantly higher risk for syphilis than patients aged 24 or younger. HIV infections among the elderly have become increasingly common in China in recent years $[7,42,43]$. The possible reasons for higher risks for HIV and STIs among elderly may include increasing use of commercial sex, infrequent condom use and low uptake of STIs testing [42-44].

Our study has limitations. Firstly, we did not collect data on sexual behaviors and therefore couldn't evaluate the relationship between syphilis and sexual behaviors. Secondly, the participants were a convenience sample of PLWHA who lived in Shenyang city. Results from this study may not represent all individuals who are living with HIV/AIDS in China. Thirdly, higher loss to followup is another challenge in our study. By the end of the study period, about $21.7 \%$ of the participants were lost to follow-up, and this may cause selection bias. Fourthly, because HIV and syphilis are sensitive topic for participants, this study cannot exclude social desirability bias. Our study, with data on both syphilis prevalence and incidence in HIV-infected population, provides significant evidence for improving HIV/STIs prevention interventions and care, albeit with above-mentioned limitations.

\section{Conclusions}

The prevalence and incidence of concurrent syphilis were both moderately high among PLWHA in Northeast China. Results from this program suggest that receiving ART, older age, and MSM status were independent risk factors for both prevalent and incident syphilis infection. Interventions focusing on the detection and treatment of syphilis are urgently needed for PLWHA in China, especially MSM who are at high risk for syphilis.

\section{Competing interests}

This study was funded by the Mega-Projects of National Science Research for the 12th Five-Year Plan (2012ZX10001006); Scientific Research Projects of Education Department of Liaoning Province (L2013312); "Innovation Team Development Program 2012" of The Ministry of Education. The funding organization had no role in the development of study design or in the collection, analysis, and interpretation of data. The authors declare that they have no competing interests. 


\section{Authors' contributions}

Conceived and designed the experiments: QHH JJX HS participated in the design of the study. QHH JL JZ HBD performed the study and experiments. QHH JZ analyzed the data; QHH wrote the manuscript. JJX HCZ HZQ YL SRL YJJ HS NW revised the manuscript. All authors read and approved the final manuscript.

\section{Acknowledgements}

The authors extend their sincere thanks to all participants in the study. The authors also thank Christiana Meng Zhang from the Georgetown University School of Medicine who helped review this manuscript.

\section{Author details}

${ }^{1}$ Key Laboratory of AIDS Immunology of National Health and Family Planning Commission, Department of Laboratory Medicine, The First Affiliated Hospital, China Medical University, Shenyang 110001, P. R. China. ${ }^{2}$ Collaborative Innovation Center for Diagnosis and Treatment of Infectious Diseases, Hangzhou, China. ${ }^{3}$ School of Public Health and Community Medicine, The University of New South Wales, Sydney 2052, Australia. ${ }^{4}$ Vanderbilt Institute for Global Health, Vanderbilt University, Nashville, TN, USA. ${ }^{5}$ English Department, University of Tennessee at Chattanooga, Chattanooga, TN, USA. ${ }^{6}$ National Center for AIDS/STD Control and Prevention, Chinese Center for Disease Control and Prevention, Beijing, China.

Received: 23 September 2014 Accepted: 24 November 2014 Published online: 04 December 2014

\section{References}

1. Syphilis prevention and control planning in China (2010-2020) [http://www.nhfpc.gov.cn/jkj/s3585/201006/5947fc5935bc4908bc1939 b1663141fc.shtml]

2. Chen ZQ, Zhang GC, Gong XD, Lin C, Gao X, Liang GJ, Yue XL, Chen XS, Cohen MS: Syphilis in China: results of a national surveillance programme. Lancet 2007, 369(9556):132-138.

3. Chen XS, Peeling RW, Yin YP, Mabey DC: The epidemic of sexually transmitted infections in China: implications for control and future perspectives. BMC Med 2011, 9:111.

4. Sexually Transmitted Disease Surveillance 2011. December 2012. [http://www.cdc.gov/std/stats11/surv2011.pdf]

5. Savage EJ, Marsh K, Duffell S, Ison CA, Zaman A, Hughes G: Rapid increase in gonorrhoea and syphilis diagnoses in England in 2011. Euro Surveill 2012; 17(29)

6. Men who have sex with men (MSM) with active syphilis Data by country. 2014 [http://apps.who.int/gho/data/node.main.A1361STI]

7. 2012 China AIDS response progress report. Beijing: PRC Ministry of Health, 31 March 2012. [http://www.unaids.org/en/dataanalysis/ knowyourresponse/countryprogressreports/2012countries/ce_CN_ Narrative_Report\%5B1\%5D.pdf.]

8. The HIV/AIDS prevention and control work background in our country [http://www.nhfpc.gov.cn/jkj/s3586/201312/2b871ccd2ef446eb 9542875d3d68bbca.shtml]

9. Padian NS, McCoy SI, Karim SS, Hasen N, Kim J, Bartos M, Katabira E, Bertozzi SM, Schwartlander B, Cohen MS: HIV prevention transformed: the new prevention research agenda. Lancet 2011, 378(9787):269-278.

10. Montano DE, Phillips WR, Kasprzyk D, Greek A: STD/HIV prevention practices among primary care clinicians: risk assessment, prevention counseling, and testing. Sex Transm Dis 2008, 35(2):154-166.

11. Bunnell R, Mermin J, De Cock KM: HIV prevention for a threatened continent: implementing positive prevention in Africa. JAMA 2006 296(7):855-858.

12. Crepaz N, Lyles CM, Wolitski RJ, Passin WF, Rama SM, Herbst JH, Purcell DW, Malow RM, Stall R: Do prevention interventions reduce HIV risk behaviours among people living with HIV? A meta-analytic review of controlled trials. AIDS 2006, 20(2):143-157.

13. Cohen MS, Chen YQ, McCauley M, Gamble T, Hosseinipour MC, Kumarasamy N, Hakim JG, Kumwenda J, Grinsztejn B, Pilotto JH, Godbole SV, Mehendale S, Chariyalertsak S, Santos BR, Mayer KH, Hoffman IF, Eshleman SH, Piwowar-Manning E, Wang L, Makhema J, Mills LA, de Bruyn G, Sanne I, Eron J, Gallant J, Havlir D, Swindells S, Ribaudo H, Elharrar V,
Burns $D$, et al: Prevention of HIV-1 infection with early antiretroviral therapy. N Engl J Med 2011, 365(6):493-505.

14. Jia Z, Mao Y, Zhang F, Ruan Y, Ma Y, Li J, Guo W, Liu E, Dou Z, Zhao Y Wang L, Li Q, Xie P, Tang H, Han J, Jin X, Xu J, Xiong R, Zhao D, Li P, Wang X, Wang L, Qing Q, Ding Z, Chen RY, Liu Z, Shao Y: Antiretroviral therapy to prevent HIV transmission in serodiscordant couples in China (2003-11): a national observational cohort study. Lancet 2013, 382(9899):1195-1203.

15. Graham SM, Holte SE, Dragavon JA, Ramko KM, Mandaliya KN, McClelland RS, Peshu NM, Sanders EJ, Krieger JN, Coombs RW: HIV-1 RNA may decline more slowly in semen than in blood following initiation of efavirenz-based antiretroviral therapy. PLoS One 2012, 7(8):e43086.

16. Lambert-Niclot S, Tubiana R, Beaudoux C, Lefebvre G, Caby F, Bonmarchand M, Naouri M, Schubert B, Dommergues M, Calvez V, Flandre P, Poirot C, Marcelin AG: Detection of HIV-1 RNA in seminal plasma samples from treated patients with undetectable HIV-1 RNA in blood plasma on a 2002-2011 survey. AIDS 2012, 26(8):971-975.

17. Elford J, Bolding G, Maguire M, Sherr L: Combination therapies for HIV and sexual risk behavior among gay men. J Acquir Immune Defic Syndr 2000, 23(3):266-271.

18. Dukers NHTM, Goudsmit J, de Wit JBF, Prins M, Weverling G-J, Coutinho RA: Sexual risk behaviour relates to the virological and immunological improvements during highly active antiretroviral therapy in HIV-1 infection. AIDS 2001, 15(3):369-378.

19. Imrie J, Lambert N, Mercer C, Copas A, Phillips A, Dean G, Watson R, Fisher M: Refocusing health promotion for syphilis prevention: results of a case-control study of men who have sex with men on England's south coast. Sex Transm Infect 2006, 82(1):80-83.

20. Tucker JD, Yin YP, Wang B, Chen XS, Cohen MS: An expanding syphilis epidemic in China: epidemiology, behavioural risk and control strategies with a focus on low-tier female sex workers and men who have sex with men. Sex Transm Infect 2011, 87(Suppl 2):ii16-ii18.

21. Tang W, Huan X, Mahapatra T, Tang S, Li J, Yan H, Fu G, Yang H, Zhao J, Detels R: Factors associated with unprotected anal intercourse among men who have sex with men: results from a respondent driven sampling survey in Nanjing, China, 2008. AIDS Behav 2013, 17(4):1415-1422.

22. Buchacz K, Patel P, Taylor M, Kerndt PR, Byers RH, Holmberg SD, Klausner JD: Syphilis increases HIV viral load and decreases $\mathrm{CD}^{+}$cell counts in HIV-infected patients with new syphilis infections. AIDS 2004, 18(15):2075-2079.

23. Zhu H, Napravnik S, Eron JJ, Cole SR, Ma Y, Wohl DA, Dou Z, Zhang Y, Liu Z, Zhao D, Yu L, Liu X, Cohen MS, Zhang F: Decreasing excess mortality of HIV-infected patients initiating antiretroviral therapy: comparison with mortality in general population in China, 2003-2009. J Acquir Immune Defic Syndr 2013, 63(5):e150-e157.

24. Zhang F: China Free Antiretroviral Therapy Manual. 2012th edition. Beijing: People's Medical Publishing House; 2012.

25. Ko NY, Liu HY, Lee HC, Lai YY, Chang CM, Lee NY, Chen PL, Wu CJ, Ko WC: One-year follow-up of relapse to risky behaviors and incidence of syphilis among patients enrolled in the HIV case management program. AIDS Behav 2011, 15(5):1067-1074.

26. Gao K, Wang C, Chen L, Xu H, Han Z: Syphilis infection analysis in people living with HIV/AIDS in Guangzhou, 2011. South China J Prev Med 2013, 39(2):32-35.

27. Luo P, Liu Z, Zhao Y: Present situation of HIV, HCV and TP coinfection in HIV-infected patients in Liuzhou Area. J Trop Med 2008, 8(9):917-919.

28. Kalichman SC, Pellowski J, Turner C: Prevalence of sexually transmitted co-infections in people living with HIV/AIDS: systematic review with implications for using HIV treatments for prevention. Sex Transm Infect 2011, 87(3):183-190.

29. Park WB, Jang H-C, Kim S-H, Kim HB, Kim NJ, Oh M-d, Choe KW: Effect of highly active antiretroviral therapy on incidence of early syphilis in HIV-infected patients. Sex Transm Dis 2008, 35(3):304-306.

30. Yin L, Qin GM, Ruan $Y H$, Zhang L, Hao ON, Chen XH, Jiang ZO, Song $B L$, Liu SZ, Cao XY, Hao C, Chen KL, Shao YM: A propective cohort study on human immunodeficiency virus and syphilis seroconversion among injecting drug users. Chin J Epidemiol 2006, 27(4):293-297.

31. Tian LG, Ma ZE, Ruan YH, Cao XY, Huang JP, Wang DR, Zhu GP, Yao HM, Han L, Hao C, Yin L, Liang S, Qin GM, Chen KL, Wang J, Wang N, Shao YM: Incidence rates of human immunodeficiency virus and syphilis as well as the rate of retention in a 6-month follow-up study of female sex workers 
in areas with heavy drug use in Xichang of Sichuan province, China. Chin J Epidemiol 2006, 27(11):939-942.

32. Arora PN, Sastry CVR: HIV infection and genital ulcer disease. Indian J Sex Transm Dis 1992, 13(2):71-73.

33. Morin SF, Shade SB, Steward WT, Carrico AW, Remien RH, Rotheram-Borus MJ, Kelly JA, Charlebois ED, Johnson MO, Chesney MA: A behavioral intervention reduces HIV transmission risk by promoting sustained serosorting practices among HIV-infected men who have sex with men. J Acquir Immune Defic Syndr 2008, 49(5):544-551.

34. Stolte IG, Dukers NHTM, de Wit JBF, Fennema JSA, Coutinho RA: Increase in sexually transmitted infections among homosexual men in Amsterdam in relation to HAART. Sex Transm Infect 2001, 77(3):184-186.

35. Crepaz N, Hart TA, Marks G: Highly active antiretroviral therapy and sexual risk behavior. JAMA 2004, 292(2):224-236.

36. Cicconi P, Cozzi-Lepri A, Orlando G, Matteelli A, Girardi E, Degli Esposti A Moioli C, Rizzardini G, Chiodera A, Ballardini G: Recent acquired STD and the use of HAART in the Italian Cohort of Naive for Antiretrovirals (I. Co. NA): analysis of the incidence of newly acquired hepatitis B infection and syphilis. Infection 2008, 36(1):46-53.

37. Huang YF, Nelson KE, Lin YT, Yang CH, Chang FY, Lew-Ting CY: Syphilis Among Men Who Have Sex With Men (MSM) in Taiwan: its association with HIV prevalence, awareness of HIV status, and use of antiretroviral therapy. AIDS Behav 2013, 17(4):1406-1414.

38. Katz MH, Schwarcz SK, Kellogg TA, Klausner JD, Dilley JW, Gibson S, McFarland W: Impact of highly active antiretroviral treatment on HIV seroincidence among men who have sex with men: San Francisco. Am J Public Health 2002, 92(3):388-394.

39. Branger J, van der Meer JTM, van Ketel RJ, Jurriaans S, Prins JM: High incidence of asymptomatic syphilis in HIV-infected MSM justifies routine screening. Sex Transm Dis 2009, 36(2):84-85.

40. Choi K-H, Gibson DR, Han L, Guo Y: High levels of unprotected sex with men and women among men who have sex with men: a potential bridge of HIV transmission in Beijing, China. AIDS Educ Prev 2004, 16(1: Special issue):19-30.

41. Li HM, Peng R, Li J, Yin YP, Wang BX, Cohen MS, Chen XS: HIV incidence among men who have sex with men in China: a meta-analysis of published studies. PLoS One 2011, 6(8):e23431.

42. Feng Y, Wu Z, Detels R, Qin G, Liu L, Wang X, Wang J, Zhang L: HIV/STD prevalence among men who have sex with men in Chengdu, China and associated risk factors for HIV infection. J Acquir Immune Defic Syndr 2010, 53(Suppl 1):S74-S80.

43. Chen X, Li X, Qin B, Zheng J, He J, Wang L, Wang N, Hsu A, Khoshnood K: Older HIV-positive adults in Xiangxi, China: infection modes and associated risk factors. Sex Transm Dis 2012, 39(9):716-719.

44. Pearline RV, Tucker JD, Yuan L-F, Bu J, Yin Y-P, Chen X-S, Cohen MS: Sexually transmitted infections among individuals over fifty years of age in China. AIDS Patient Care STDS 2010, 24(6):345-347.

doi:10.1186/s12879-014-0658-1

Cite this article as: Hu et al: Risk factors associated with prevalent and incident syphilis among an HIV-infected cohort in Northeast China. BMC Infectious Diseases 2014 14:658.

\section{Submit your next manuscript to BioMed Central and take full advantage of:}

- Convenient online submission

- Thorough peer review

- No space constraints or color figure charges

- Immediate publication on acceptance

- Inclusion in PubMed, CAS, Scopus and Google Scholar

- Research which is freely available for redistribution

Submit your manuscript at www.biomedcentral.com/submit
Ciomed Central 